\title{
Risco de contágio ocupacional pelo sangue do doente durante os procedimentos neurocirúrgicos
}

\author{
Flávia Elisa Antunes Lemes de Oliveira*, Claudia Reiko Akamoto Sato*, \\ Milton K. Shibata**
}

Centro de Estudos em Enfermagem e Serviço de Neurocirurgia do Hospital 9 de Julho, São Paulo, SP

\section{RESUMO}

A exposição ocupacional dos profissionais da área de saúde às doenças transmitidas pelo sangue tem sido preocupação crescente. Este estudo prospectivo foi realizado com o objetivo de avaliar a freqüência com que os profissionais que atuam na sala de operações neurocirúrgicas possam ser potencialmente contaminados através de contato direto com o sangue do doente. A ocorrência do contato dos profissionais com o sangue do doente, em 62 operações consecutivas, foi anotada em protocolo pré-estabelecido pela enfermeira da neurocirurgia do centro cirúrgico. O cirurgião foi o elemento da equipe cujo contato evidente com o sangue (através de ferimento perfurocortante ou através de contato cutâneo-mucoso sem ferimento) ocorreu com maior freqüência. Nesse profissional, contatos evidentes ocorreram, pelo menos uma vez, em 19,3\% das operações realizadas, um terço deles por meio de ferimentos perfurocortantes. Seguiram-no, em ordem decrescente, a instrumentadora $(9,7 \%)$ e a enfermeira $(6,4 \%)$. Nenhum profissional que atua na sala de operações esteve livre do risco.

Este estudo demonstrou que a incidência, no cirurgião e na instrumentadora, de pelo menos um episódio de contato direto com o sangue, ou com outro material orgânico contaminado pelo sangue do doente, é elevada. Há, portanto, a necessidade de se dispor de protocolos escritos para notificação imediata das exposições ocupacionais aos patógenos transmitidos pelo sangue do doente. A notificação é importante para que o Serviço de Controle da Infecção Hospitalar da instituição analise os riscos de contágio e, se necessário, institua a profilaxia recomendada. É importante, também, que se adotem medidas, naquele ambiente, visando à prevenção de novos acidentes.

\section{PALAVRAS-CHAVE}

Exposição ocupacional. Sala de cirurgia.

\section{ABSTRACT}

Risk of occupational blood exposures among members of the operative team during neurosurgical procedures

Blood exposures are clearly recognized as a risk for healthcare personnel in the operating room. Nurses trained to work in neurosurgical operating room at the Hospital Nove de Julho, São Paulo, Brazil, carried out this prospective study. The occurrence of contact with blood among the operative team during neurosurgical procedures was collected under the surveillance of the operating room nurse in 62 consecutive routine procedures (27 craniotomies, 17 laminectomies, 9 trepanations, 6 shunt procedures and 3 carotid endarterectomies). Blood contacts were defined as percutaneous (accidental cuts or punctures with blood contaminated instruments) and muco-cutaneous (visible blood on the apparently intact skin or mucous membrane of an operative team member).

The senior surgeon was the element of the team that suffered the highest incidence of blood contact. Blood contact occurred, at least once, in 19.3\% of the surgeries in this professional, a third of which through percutaneous exposure. He was followed by scrub nurse (contact with blood in $9.7 \%$ of the procedures); operating room registered nurse (6.4\%), assistant surgeon (3.2\%), anesthetist (3.2\%) and circulating nurse (1.6\%). The percentage of blood contact observed in our study is too high if compared to the results of a multicenter study reported by White and Lynch. Moreover, if we consider that our study excluded the emergency procedures and that all the participating surgeons,

* Enfermeira de Neurocirurgia.

** Neurocirurgião. 
including the assistants, are in practice, for at least, 15 years. We wonder if the modern high rotation powerful drills and sharp instruments have not increased the risk of exposure to blood-borne pathogens among the operative team in neurosurgery.

\section{KEY WORDS}

Occupational exposure. Operating room.

\section{Introducão}

A exposição ocupacional dos profissionais da área de saúde aos patógenos transmitidos pelo sangue tem sido preocupação crescente, acompanhando o aumento da prevalência da AIDS, da hepatite B e da hapatite C na população. Em 1988, o relato do Centers of Disease Control (CDC) dos EUA enfatizou dois pontos fundamentais relacionados a esses riscos profissionais:

1. o sangue é, isoladamente, a fonte mais importante de contágio pelo HIV e pelo HBV (vírus da hepatite B) entre esses profissionais;

2. a prevenção do contágio dos profissionais por esses patógenos deve ser fundamentada no maior número de recursos possíveis para evitar o contato com sangue e na imunização contra o $\mathrm{HBV}^{4}$.

A neurocirurgia moderna, aliada à tecnologia atual, incorporou inúmeros instrumentos que são utilizados durante os procedimentos operatórios. O craniótomo e o drill de alta rotação e potência proporcionam, ao cirurgião, craniotomias rápidas com pouco esforço. Entretanto, durante a utilização desses dispositivos, há a necessidade de irrigação contínua. A alta rotação desses instrumentos faz com que a solução utilizada na irrigação, misturada ao sangue e ao pó de osso do paciente, respingue de volta naqueles que estão no campo cirúrgico. Os instrumentos utilizados na etapa microcirúrgica da maioria dos procedimentos neurocirúrgicos permitem cortes precisos e eficientes. No entanto, a extremidade perfurocortante desses instrumentos, muito afiados e de dimensões reduzidas, é causa adicional de ferimentos e acidentes nos profissionais que atuam no centro cirúrgico.

O risco de infecção pelo HIV, após exposição percutânea ao sangue contaminado, é baixo, estimado em $0,3 \%$, pelo menos dez vezes inferior ao risco de infecção pelo $\mathrm{HBV}$ e HBC ${ }^{1}$. No entanto, o HIV é o mais temido, a ponto de Heifetz ${ }^{9}$, discutindo Ethics , AIDS and the neurosurgeon, ter ponderado que, se de um lado há o dever médico de atender ao paciente com AIDS, de outro, há o direito ético da recusa do cirurgião de se expor ao risco, mesmo mínimo, de contrair doença fatal.
O presente estudo foi realizado pela Enfermagem de Neurocirurgia do Centro Cirúrgico do Hospital 9 de Julho, com o objetivo de avaliar a freqüência com que os profissionais, que atuam em procedimentos neurocirúrgicos, possam ser potencialmente contaminados por contato direto com o sangue ou com o material orgânico contendo sangue dos pacientes operados. A equipe de neurocirurgia do hospital é formada por oito neurocirurgiões e dois anestesistas, além de três instrumentadoras, duas enfermeiras de neurocirurgia e duas auxiliares de enfermagem (circulantes de sala), devidamente treinadas para atender a essa especialidade. Realiza, em média, 50 operações ao mês, somando-se os procedimentos eletivos (que incluem neurocirurgia funcional) e os de emergência. O centro cirúrgico dispõe de uma sala equipada e de uso exclusivo para neurocirurgia.

\section{Casuística e métodos}

Este estudo prospectivo abrangeu apenas os profissionais titulares envolvidos exclusivamente nos procedimentos eletivos realizados na Sala de Neurocirurgia do Centro Cirúrgico do Hospital 9 de Julho, no período de junho a outubro de 1996. Ao todo, foram realizadas 69 cirurgias com a participação de cinco neurocirurgiões, dois anestesistas, três instrumentadoras, duas enfermeiras e duas circulantes de sala de operação. Todos os profissionais envolvidos estavam cientes do estudo em andamento.

Não foram acompanhados os procedimentos realizados por três outros neurocirurgiões da equipe que se dedicam, quase exclusivamente, à neurocirurgia funcional. A maioria desses procedimentos tem início fora do centro cirúrgico, por exemplo, com a colocação do quadro de estereotaxia nos setores de tomografia computadorizada ou de ressonância magnética do hospital, dificultando a aplicação do protocolo preestabelecido.

O protocolo estabelecia que a ocorrência do contato dos profissionais com o sangue e com outros materiais orgânicos do paciente seria sempre anotada pela enfermeira da neurocirurgia do centro cirúrgico. Foram considerados dois tipos de contato:

1. contato evidente: incluíram-se os ferimentos perfurocortantes sofridos pelos profissionais durante os procedimentos, e os contatos cutâneo-mucosos, sem ferimentos, mas caracterizados pela presença, visível a olho nu, de sangue ou outros materiais orgânicos contaminados pelo sangue do doente, na pele ou na mucosa dos profissionais; 
2. contato presumível: incluíram-se, como contatos presumíveis, as perfurações nas luvas, percebidas ou não durante o ato cirúrgico, porém, sem a constatação de sangue visível na região correspondente da mão do profissional que a utilizou.

O contato evidente foi constatado pela observação direta durante e ao término de cada procedimento. Todas as luvas utilizadas e consideradas íntegras foram identificadas e submetidas ao método do "jato d'água” para se definir a presença ou não de perfurações não detectadas durante o uso. Essas observações foram feitas exclusivamente pelas enfermeiras da neurocirurgia.

Foi considerada, na análise dos resultados, apenas uma única ocorrência de cada tipo de contato para cada função profissional, em cada procedimento. Não foram consideradas as repetições do mesmo tipo de contato, durante um procedimento, no mesmo profissional. $\mathrm{Na}$ eventualidade da concomitância de ferimento perfurocortante com outros tipos de contato sem lesão, foi considerado apenas o ferimento (ocorrência potencialmente mais grave).

O tipo de atividade que estava sendo realizada quando ocorreu a contaminação, o profissional acometido, o tipo e a duração da cirurgia foram analisados.

Foram incluídos neste estudo, os dados obtidos em 62 das 69 cirurgias realizadas. Os dados de sete operações foram excluídos por haver falha no preenchimento do protocolo. A relação das cirurgias realizadas durante o estudo encontra-se no quadro 1.

Não se fez teste anti-HIV pré ou pós-operatório dos doentes operados, bem como nenhum era, sabidamente, portador da doença.

\begin{tabular}{lc}
\hline \multicolumn{2}{c}{$\begin{array}{c}\text { Quadro 1 } \\
\text { Relação das cirurgias }\end{array}$} \\
\hline Tipo de cirurgia & $\mathbf{n}^{\mathbf{0}}$ \\
\hline Craniotomia & 27 \\
Laminectomia & 17 \\
Trepanação & 9 \\
Derivação ventricular interna & 6 \\
Endarterctomia carotídea & 3 \\
\hline Total & 62 \\
\hline
\end{tabular}

\section{Resultados}

A freqüência em que ocorreu o contato evidente de cada profissional com o sangue do paciente está apresentada na tabela 1 . O cirurgião foi o elemento da equipe que mais teve contato com o sangue. Nesse profissional, contatos evidentes ocorreram, pelo menos uma vez, em 19,3\% das cirurgias realizadas, um terço por meio de ferimentos perfurocortantes. Seguiram-no, em ordem decrescente, a instrumentadora $(9,7 \%)$ e a enfermeira (6,4\%). Além do cirurgião, foram acometidos por ferimentos, embora mais raramente, a instrumentadora e o anestesista.

As principais causas ou fontes do contato evidente e as respectivas freqüências relativas estão relacionadas na tabela 2. Na maioria das vezes (62,9\%), o contato evidente ocorreu durante a manipulação de instrumentos cirúrgicos contaminados. Todos os integrantes da equipe expuseram-se ao sangue do doente por meio de algum instrumento, principalmente a instrumentadora.

\begin{tabular}{|c|c|c|c|c|c|c|}
\hline \multicolumn{7}{|c|}{$\begin{array}{c}\text { Tabela } 1 \\
\text { Freqüência de contato evidente em } 62 \text { cirurgias }\end{array}$} \\
\hline Tipo & Cirurgião & Assistente & Instrumentadora & Anestesista & Enfermeira & Circulante \\
\hline Sem ferimento & $8(12,9 \%)$ & $2(3,2 \%)$ & $5(8,1 \%)$ & $1(1,6 \%)$ & $4(6,4 \%)$ & $1(1,6 \%)$ \\
\hline Com ferimento & $4(6,4 \%)$ & - & $1(1,6 \%)$ & $1(1,6 \%)$ & - & - \\
\hline Total & $12(19,3 \%)$ & $2(3,2 \%)$ & $6(9,7 \%)$ & $2(3,2 \%)$ & $4(6,4 \%)$ & $1(1,6 \%)$ \\
\hline
\end{tabular}

\begin{tabular}{|c|c|c|c|c|c|c|c|}
\hline \multicolumn{8}{|c|}{$\begin{array}{c}\text { Tabela } 2 \\
\text { Fontes ou causas dos } 27 \text { contatos evidentes e respectivas freqüências relativas }\end{array}$} \\
\hline Fonte & Cirurgião & Assistente & Instrumentadora & Anestesista & Enfermeira & Circulante & Total \\
\hline Instrumental & $4(14,8 \%)$ & $2(7,4 \%)$ & $5(18,5 \%)$ & $2(7,4 \%)$ & $3(11,1 \%)$ & $1(3,7 \%)$ & $17(62,9 \%)$ \\
\hline Campo operatório & $7(25,9 \%)$ & - & - & - & - & - & $7(25,9 \%)$ \\
\hline \multicolumn{8}{|c|}{ Cuidados pré e pós-operatórios } \\
\hline imediatos & $1(3,7 \%)$ & - & - & - & $1(3,7 \%)$ & - & $2(7,4 \%)$ \\
\hline Não identificada & - & - & $1(3,7 \%)$ & - & - & - & $1(3,7 \%)$ \\
\hline Total & $12(44,4 \%)$ & $2(7,4 \%)$ & $6(22,2 \%)$ & $2(7,4 \%)$ & $4(14,8 \%)$ & $1(3,7 \%)$ & $27(100 \%)$ \\
\hline
\end{tabular}


No cirurgião, a maioria dos contatos teve origem diretamente do campo operatório. O cirurgião foi o único contaminado pelo respingo de sangue ou pelo pó de osso durante a diérese, oriundos de vasos do couro cabeludo e da solução de irrigação durante o uso do craniótomo ou do drill. A região mais atingida foi a face.

Em freqüência muito menor (7,4\%), o contágio ocorreu durante a manipulação do paciente nos cuidados pré e pós-operatórios imediatos, dentro da sala de operação.

O índice de ocorrência de contatos presumíveis evidenciados pela presença de perfurações nas luvas, percebidas ou não pelo profissional que as utilizou, está apresentado na tabela 3. O cirurgião também foi o elemento que apresentou maior risco de contato presumível. As perfurações nas luvas utilizadas pelo cirurgião, sem sangue visível na região correspondente da mão, foram notadas pelo menos uma vez em 37\% das cirurgias. O mesmo ocorreu nas luvas da instrumentadora, em 29\% das cirurgias, e mais raramente, nas do auxiliar. O cirurgião e seu auxiliar, ao contrário da instrumentadora, não perceberam a existência desses furos na maioria das vezes (Tabela 3).

\begin{tabular}{lccc}
\hline \multicolumn{4}{c}{ Tabela 3} \\
\multicolumn{4}{c}{$\begin{array}{c}\text { Perfurações encontradas nas luvas cirúrgicas } \\
\text { (contato presumível durante }\end{array}$} \\
\hline 62 procedimentos) \\
\hline Componentes da equipe & Percebida & Não percebida & Total \\
\hline Cirurgião & $4(6,4 \%)$ & $19(30,6 \%)$ & $23(37,0 \%)$ \\
Auxiliar & $2(3,2 \%)$ & $7(11,2 \%)$ & $9(15,5 \%)$ \\
Instrumentadora & $8(12,9 \%)$ & $10(16,1 \%)$ & $18(29,0 \%)$ \\
\hline Total & $14(22,5 \%)$ & $36(57,9 \%)$ & $47(80,5 \%)$ \\
\hline
\end{tabular}

A tabela 4 mostra a distribuição da freqüência de contato evidente e/ou presumível, em pelo menos um dos profissionais da sala de operação, em relação ao tipo de cirurgia. A incidência de contato evidente ou presumível, acometendo pelo menos um elemento da equipe, é cerca de duas vezes maior nas craniotomias $(81,5 \%)$ quando comparada às laminectomias $(47 \%)$, às trepanações (44,4\%) e às derivações (50\%).

\begin{tabular}{lcc}
\hline \multicolumn{3}{c}{ Tabela 4} \\
Incidência de contato observada & em cada tipo de cirurgia \\
\hline Tipo de cirurgia & $\mathbf{n}^{\circ}$ & Contato \\
\hline Craniotomia & 27 & $22(81,5 \%)$ \\
Laminectomia & 17 & $8(47,0 \%)$ \\
Trepanação & 9 & $4(44,4 \%)$ \\
Derivação & 6 & $3(50,0 \%)$ \\
Endarterectomia & 3 & $3(100 \%)$ \\
\hline Total & 62 & $40(64,5 \%)$ \\
\hline
\end{tabular}

A relação entre a duração do procedimento e o risco de contato está apresentada na tabela 5.

\begin{tabular}{lcc}
\hline \multicolumn{3}{c}{ Tabela 5} \\
Relação entre duração da cirurgia & e freqüência de contato \\
\hline Duração & $\mathbf{n}^{\circ}$ & Contato \\
\hline Até 3 horas & 41 & $25(60,9 \%)$ \\
Mais de 3 horas & 21 & $15(71,4 \%)$ \\
\hline Total & 62 & $40(64,5 \%)$ \\
\hline
\end{tabular}

\section{Discussão}

Estudos prospectivos, acompanhando diversos profissionais da área de saúde (não somente aqueles que atuam na sala de operações), estimam que o risco de transmissão, após exposição percutânea ao sangue infectado pelo HIV, é de aproximadamente $0,3 \%{ }^{1} \mathrm{e}$, após contato do sangue infectado com membranas mucosas, de $0,1 \%{ }^{10}$. Apesar de a transmissão do HIV por meio da exposição da pele ter sido documentada, o risco desse tipo de contágio deve ser menor, mas não está quantificado, assim como não está determinado o risco de contágio após o contato com secreções e com outros materiais orgânicos que não sejam o sangue de doentes HIV-positivos. Até junho de 1997, haviam sido notificados, ao Centers for Disease Control nos EUA, 52 casos documentados de soroconversão em profissionais da área de saúde, associados à exposição ocupacional ao HIV: em 47, o contato havia sido direto com o sangue infectado; em um, com secreção visivelmente sanguinolenta; em três, com concentrado do vírus no laboratório; noutro, não foi especificado. Em 45, o contato havia sido percutâneo; em cinco, o contato foi muco-cutâneo; um havia sofrido contato percutâneo e muco-cutâneo; noutro, não foi determinada a via de contato. O objeto responsável pelo contágio percutâneo foi a agulha, em 41 casos; artefatos de vidro que se quebraram, em dois; bisturi, em um; e objeto cortante não identificado, noutro ${ }^{7}$.

Outros 114 possíveis casos de contágio ocupacional pelo HIV em profissionais da área de saúde estavam registrados até aquela data no $\mathrm{CDC}^{7}$.

Estudos epidemiológicos e laboratoriais sugerem que muitos fatores influenciam o risco de se contrair HIV após ferimento ocupacional percutâneo com o sangue infectado. O risco aumenta, proporcionalmente, com a quantidade do sangue contaminado com o qual ocorreu o contato (evidenciado pela presença visível de sangue do doente no instrumento que provocou o ferimento), com a profundidade do ferimento e com 0 estado do doente na evolução da doença. A exposição ocupacional de ferimentos profundos a grandes 
volumes de sangue de doentes, em fases avançadas da doença (nos quais a carga viral está provalvelmente elevada), deve exceder o risco médio, estimado em $0,3 \%$ de contágio $3,5,12$.

Visando à determinação do risco de exposição ocupacional ao sangue, entre os profissionais que atuam em salas de operação, foi realizado, em 1992, um estudo multicêntrico envolvendo 8.502 cirurgias realizadas em nove hospitais dos EUA ${ }^{14}$. Nesse estudo, foi observado que o contato dos profissionais da sala cirúrgica com o sangue do doente ocorreu em 10,2\% dos procedimentos, e que o contato cutâneo (pele íntegra) foi cinco vezes mais freqüente que o contato parenteral (aqui incluídos, além dos ferimentos, os contatos com pele não íntegra e mucosa). O cirurgião foi o profissional sob maior risco, e mais da metade das exposições cutâneas ou percutâneas com o sangue ocorreu nele. Além disso, esse estudo concluiu que o risco do contato com sangue é maior nos procedimentos de duração maior que 90 minutos e nos procedimentos de emergência do que naqueles eletivos ${ }^{14}$.

Nosso estudo envolveu apenas as cirurgias realizadas sob condições ideais de trabalho da equipe, em sala cirúrgica própria, com pessoal fixo e treinado para os procedimentos neurocirúrgicos. Foram excluídas as cirurgias de urgência e mesmo as eletivas, quando realizadas em outras salas, nas quais atuam profissionais de enfermagem, que não estavam préestabelecidas no protocolo. As repetições do mesmo evento durante o mesmo procedimento, não foram compiladas como agravante do risco, para facilidade do cálculo. Mesmo assim, a ocorrência de contato dos profissionais com o sangue do doente foi elevada se comparada à relatada no estudo multicêntrico ${ }^{14}$. A nossa equipe utilizou a seguinte paramentação cirúrgica: a máscara, o gorro, o avental, as luvas cirúrgicas esterilizadas e os propés. Os óculos de proteção são utilizados somente quando se usa o laser e, também, quando o paciente é sabidamente portador de alguma doença transmissível, a exemplo da hepatite B/C e da AIDS, diferente do que preconiza o CDC ${ }^{4}$. Alega-se que incomodam, que embaçam e que não é possível utilizá-los com óculos de grau. Excetuando um cirurgião, os demais usam óculos de grau.

De maneira geral, no nosso estudo, o contato simples cutâneo-mucoso, com o sangue, foi 3,5 vezes mais freqüente que os acidentes perfurocortantes. $\mathrm{O}$ cirurgião foi o elemento da equipe com maior risco de contaminação, pelo menos com o dobro do risco dos demais, dado comparável ao evidenciado no estudo multicêntrico ${ }^{14}$. Na nossa investigação, contatos evidentes ocorreram no cirurgião, pelo menos uma vez, em $19,3 \%$ das cirurgias realizadas, um terço dos mesmos através de ferimentos perfurocortantes.
Seguiram-no, em ordem decrescente, a instrumentadora e a enfermeira, e não o assistente como se esperava. Embora mais raramente, a instrumentadora e o anestesista também sofreram ferimentos provocados por instrumentos contaminados pelo sangue (Tabela 1).

A via principal de contato do profissional com o sangue do doente variou conforme a função. Verificamos que, na maioria das vezes (62,9\%), o contato ocorreu através de instrumentos cirúrgicos (Tabela 2). Todos os integrantes da equipe tiveram esse tipo de contato. Entretanto, a instrumentadora foi a mais vulnerável ao contato por meio do instrumental, mais que o próprio cirurgião, provavelmente devido ao tipo de manipulação do instrumental e não à duração da manipulação. O sangue espirrado diretamente do campo cirúrgico foi responsável por mais da metade dos contatos sofridos pelo cirurgião. Essa ocorrência não foi observada em nenhum outro membro da equipe. O instrumental foi o responsável por um terço dos contatos observados no cirurgião.

O cirurgião e a instrumentadora também foram os elementos que apresentaram maior risco de contato presumível. É interessante notar que, na maioria das vezes, o cirurgião e seu auxiliar não perceberam a existência de furos. A instrumentadora mostrou-se mais atenta à ocorrência desse episódio (Tabela 3).

De acordo com os resultados obtidos, a incidência de contato evidente ou presumível, acometendo pelo menos um elemento da equipe, é cerca de duas vezes maior nas craniotomias quando comparada às laminectomias, às trepanações e às derivações. Isso, provavelmente, resulta do uso de maior número de instrumentos e do tempo prolongado do uso de equipamentos de alta rotação durante as craniotomias. O resultado obtido nas endarterectomias carotídeas não pode ser considerado devido à amostra pequena. Entretanto, pode estar relacionada à técnica empregada pelo mesmo cirurgião, de soltar o clamp com a artéria aberta para testar o fluxo retrógrado. O contato ocorreu sempre nesse mesmo momento pelo sangue jorrado diretamente da artéria.

Neste estudo, houve relação entre a duração do procedimento e o risco de contato (Tabela 5), quando os procedimentos foram divididos em dois grupos (até 3 horas e mais de 3 horas de duração). No estudo multicêntrico, foi constatado que, em cirurgias com duração maior que 90 minutos, há um risco significativamente maior da ocorrência de contato da equipe com o sangue do doente ${ }^{14}$.

No nosso meio, Lacreta ${ }^{11}$, em revisão sobre bioprevenção, acompanhou um grupo de obstetras, mostrando o alto índice de perfurações e de contaminações da equipe cirúrgica por meio de instrumentais e materiais perfurocortantes em procedimentos distintos. Citou que, às vezes, as lesões na pele não são percebidas pelo cirurgião, e que diversos autores 
chegaram à conclusão de que o risco de acidente depende da técnica empregada, da habilidade dos participantes da equipe e do equipamento utilizado.

Após o relato dos dados obtidos no estudo multicêntrico ${ }^{14}$, três hospitais que participaram desse estudo inicial continuaram a investigação durante o ano seguinte $^{15}$. Nesses, foram tomadas medidas adicionais visando à prevenção contra o contato com o sangue. A comparação dos novos dados obtidos com os do estudo anterior, nesses três hospitais, mostrou uma diminuição estatisticamente significante na incidência de contatos, em geral, com o sangue. Entretanto, proporcionalmete, a maior parte da diminuição foi a de contatos do sangue com pele íntegra. Os índices referentes ao contato percutâneo não apresentaram diferenças com significância estatística. Como no primeiro estudo, os cirurgiões sofreram o maior número de contatos com o sangue, tanto percutâneos como cutâneos. A duração da operação e a situação de emergência do procedimento continuaram como fatores presuntivos de maior risco de contato com o sangue ${ }^{14,15}$.

Está estabelecido, há mais de dez anos, que a prevenção à exposição ao sangue é o ponto primordial para evitar a infecção ocupacional pelo HIV entre profissionais da área de saúde. Recentemente, o CDC vem tentando estabelecer as normas a serem adotadas quando essa prevenção falha, isto é, o que fazer após o contato. As normas recomendadas, atualmente, pelo CDC, quando ocorre exposição, com risco potencial de um profissional da área de saúde, ao sangue de um doente, incluem: registro detalhado das condições e do tipo de contato; cuidados imediatos sobre a área do contato; avaliação dos riscos determinados, tanto pelas condições do doente como do profissional (incluindo os estados sorológicos de ambos), e o uso criterioso de profilaxia anti-retroviral. Não se tem, ainda, a avaliação dos resultados dessa profilaxia pósexposição ${ }^{7}$.

O contágio ocupacional, documentado pelo CDC, provocou síndrome compatível à infecção primária pelo HIV em 81\% dos casos, 25 dias após a exposição, em média ${ }^{7}$. Em 95\%, a soroconversão ocorre dentro de seis meses, tal qual o observado em pessoas que adquirem o HIV por outras formas ${ }^{2}$. O CDC considera que o contágio ocupacional deva ser considerado urgência médica para assegurar a administração, em tempo, da profilaxia pós-exposição.

\section{Conclusão}

Este estudo demostrou que a incidência, no cirurgião e na instrumentadora, de pelo menos um episódio de contato direto com o sangue, ou com outro material orgânico contaminado pelo sangue do doente, é elevada. Foi, seguramente, muito maior que aquela que havíamos estimado baseados na lembrança do registro voluntário na nossa memória. Apesar de todos os cirurgiões que participaram do estudo exercerem a especialidade há mais de 15 anos, contaminaram-se, diretamente, em quase $20 \%$ dos procedimentos e, as instrumentadoras, em cerca de $10 \%$. Nenhum profissional que atuou na sala de operações esteve livre desse risco.

Há, portanto, a necessidade de dispor-se de protocolos escritos para notificação imediata, avaliação, aconselhamento, tratamento e seguimento das exposições ocupacionais aos patógenos transmitidos pelo sangue do doente. A notificação é importante para que o Serviço de Controle da Infecção Hospitalar analise os riscos de contágio e, se necessário, institua uma profilaxia recomendada. É importante, também, para que se adotem medidas naquele ambiente visando à prevenção de novos acidentes.

\section{Referências}

1. BELL DM: Occupational risk of human immunodeficiency virus infection in healthcare workers: an overview. Am J Med 102 (suppl 5B): 9-15,1997.

2. BUSCH MP, SATTEN GA: Time course of viremia and antibody seroconvertion following human immunodeficiency virus exposure. Am J Med 102 (Suppl 5B):117-24, 1997

3. CARDO DM, CULVER DH,CIESIELSKI CA: A case control study of HIV serconversion in healthcare workers after percutaneous exposure. N Engl J Med 337:1485-90, 1997.

4. CENTERS FOR DISEASE CONTROL: Update:Universal precautions for prevention of transmition of human immunodeficiency virus, hepatitis B virus, and other bloodborne pathogens in healthcare settings. MMWR 37:377-82, 387-8, 1988.

5. CENTERS FOR DISEASE CONTROL: Casecontrol study of HIV seroconversion in healthcare workers after percutaneous exposure to HIV-infected blood. France, United Kingdom and United States, January 1998August 1994. MMWR 44:929-33, 1995.

6. CENTERS FOR DISEASE CONTROL: Public health service guidelines for the management of healthcare worker exposures to HIV and recommendations for postexposeure prophylaxis. MMWR 47:1-28, 1998.

7. CENTERS FOR DISEASE CONTROL: Update: human immunodeficiency virus infection in healthcare workers exposed blood of infected patients. MMWR 36:285-9, 1993.

8. GARNER JS, HOSPITAL INFECTION CONTROL PRACTICES ADVISORY COMMITTE: Guideline for isolation precautions in hospitals. Infect Control Hosp Epidemiol 17:53-80, 1990.

9. HEIFETZ MD: Ethics, AIDS and the neurosurgeon. Surg Neurol 45:299-300, 1995. 
10. IPPOLITO G, PURO V, De CARLI G: The Italian Study Group on occupational risk of HIV infection. The risk of occupational human immunodeficiency virus infection in healthcare workers. Arch Intern Med 153:1451-8, 1993.

11. LACRETA, 0. Técnica de cesárea e de episiotomia para bioprevenção da equipe cirúrgica ao HIV. Consultório Médico 28:38-42, 1995.

12. MAST ST, WOOLWINE JD, GERBENDING JL: Efficacy of gloves in reducing blood volumes transferred during simulated needlestick injury. J Infect Dis 168:1589-92, 1993.

13. TOKARS JI, MARCUS R, CULVER DH: Survillance of HIV infection and zidovudine use among healthcare workers after occupational exposure to HIV-infected blood. Ann Intern Med 118:913-9, 1993.
14. WHITE MC, LYNCH P: Blood contact in the operating room after hospital-specific data analysis and action. AmJ Inf Control 25:209-214, 1997.

15. WHITE MC, LYNCH P: Blood contact and exposures among operating room personnel: a multicenter study. Am J Infect Control 21:243-8, 1993.

Original recebido em agosto de 1997

Aceito para publicação em janeiro de 1998

\section{Endereço para correspondência:}

Serviço de Neurocirurgia do Hospital 9 de Julho

Rua Peixoto Gomide, 613/2 andar

CEP 01409-001 - São Paulo, SP 